\title{
The role of schizotypy, mental imagery, and fantasy proneness in hallucinatory reports of undergraduate students
}

Citation for published version (APA):

van de Ven, V. G., \& Merckelbach, H. L. G. J. (2003). The role of schizotypy, mental imagery, and fantasy proneness in hallucinatory reports of undergraduate students. Personality and Individual Differences, 35(4), 889-896. https://doi.org/10.1016/S0191-8869(02)00304-5

Document status and date:

Published: 01/01/2003

DOI:

10.1016/S0191-8869(02)00304-5

Document Version:

Publisher's PDF, also known as Version of record

\section{Please check the document version of this publication:}

- A submitted manuscript is the version of the article upon submission and before peer-review. There can be important differences between the submitted version and the official published version of record.

People interested in the research are advised to contact the author for the final version of the publication, or visit the DOI to the publisher's website.

- The final author version and the galley proof are versions of the publication after peer review.

- The final published version features the final layout of the paper including the volume, issue and page numbers.

Link to publication

\footnotetext{
General rights rights.

- You may freely distribute the URL identifying the publication in the public portal. please follow below link for the End User Agreement:

www.umlib.nl/taverne-license

Take down policy

If you believe that this document breaches copyright please contact us at:

repository@maastrichtuniversity.nl

providing details and we will investigate your claim.
}

Copyright and moral rights for the publications made accessible in the public portal are retained by the authors and/or other copyright owners and it is a condition of accessing publications that users recognise and abide by the legal requirements associated with these

- Users may download and print one copy of any publication from the public portal for the purpose of private study or research.

- You may not further distribute the material or use it for any profit-making activity or commercial gain

If the publication is distributed under the terms of Article $25 \mathrm{fa}$ of the Dutch Copyright Act, indicated by the "Taverne" license above, 


\title{
The role of schizotypy, mental imagery, and fantasy proneness in hallucinatory reports of undergraduate students
}

\author{
Vincent van de Ven ${ }^{\mathrm{a}, *}$, Harald Merckelbach ${ }^{\mathrm{b}}$ \\ a Department of Psychiatry, Division of Clinical Neurophysiology, Johann Wolfgang Goethe University, \\ Frankfurt am Main, Germany \\ ${ }^{\mathrm{b}}$ Department of Experimental Psychology, Maastricht University, the Netherlands
}

Received 24 April 2002; received in revised form 1 August 2002; accepted 9 October 2002

\begin{abstract}
Using the White Christmas task, we examined in a sample of undergraduate students $(N=111)$ individual differences between participants who reported "hallucinatory experiences" and those who did not. For this purpose, we used individual difference measures tapping the following constructs: schizotypy, predisposition to hallucinate, mental imagery, and fantasy proneness. Participants who reported hallucinatory experiences during the White Christmas task scored higher on mental imagery and fantasy proneness as compared to those who did not report such experiences. Furthermore, self-reported imagery ability and fantasy proneness were strongly related. However, logistic regression analysis indicated that fantasy proneness was the best predictor of hallucinatory reports. Implications of these findings for the study of hallucinatory reports in non-clinical populations are discussed.
\end{abstract}

(C) 2003 Elsevier Ltd. All rights reserved.

Keywords: Hallucinatory reports; Fantasy proneness; Schizotypy; Mental imagery

\section{Introduction}

A number of authors have suggested that hallucinations exist on a continuum ranging from relatively benign forms to pathological manifestations as seen in schizophrenia (see review by Bentall, 1990). Indeed, several studies have indicated that a non-trivial minority of the normal population reports having had hallucinatory experiences at some point in their lives (e.g. Barrett \& Etheridge, 1992). However, it remains unclear as to how these individuals differ from those who say they have never had hallucination-like experiences. In line with the continuum-hypothesis, one

* Corresponding author at: Department of Psychiatry, Laboratory for Neuroimaging and Neurophysiology, Heinrich-Hoffmann Strasse 10, DE-60528, Frankfurt am Main, Germany. Tel.: + 49-69-6301-7634; fax: + 49-69-6301-3833. 
approach to this issue aims at identifying schizophrenia-like traits in the normal population. These traits are often referred to as "schizotypy" (e.g. Claridge \& Broks, 1984). Some studies suggest that schizotypal characteristics comprise several distinct classes of phenomena (e.g. positive schizotypy; negative schizotypy; cognitive disorganization), which correspond to clinical subdivisions seen in schizophrenia (Bentall, Claridge, \& Slade, 1989; Claridge \& Broks, 1984; Loughland \& Williams, 1997). Hallucinatory experiences are commonly assigned to positive schizotypy, a category that comprises unusual cognitive and perceptual experiences. Schizotypy in normal participants has often been investigated as a trait that bears strong relevance to schizophrenia research, as its study would offer potential insights into schizophrenia without the confounding effects of medication or institutionalization. However, the precise contribution of schizotypy to hallucinatory experiences in normals has not been thoroughly addressed.

A simple experimental test to elicit hallucinatory reports in non-clinical groups is the White Christmas task (Barber \& Calverey, 1964; Mintz \& Alpert, 1972; Young, Bentall, Slade, \& Dewey, 1987). In this task, participants are asked to close their eyes and imagine Bing Crosby's White Christmas song being played. After $30 \mathrm{~s}$, participants are interrupted and asked to rate the quality of their imagination. With this task, it has consistently been found that a non-trivial minority of normal participants report having heard the song clearly, although most of them also indicate that they do not believe the record has actually been played. When hallucinating psychiatric patients undergo the White Christmas task, they not only report more often having heard the song than healthy controls, but they also show a firm belief that the song has actually been played (Mintz \& Alpert, 1972; Young et al., 1987). This led Mintz and Alpert (1972) to conclude that the quality of an individual's mental imagery ability is a necessary, but not sufficient condition for genuine hallucinations to occur. According to these authors, only the combination of strong mental imagery ability and poor reality testing would produce pathological hallucinations.

Although there is some consensus among authors about the role of deficient reality monitoring in pathological hallucinations (e.g. Bentall, 1990; Cahill \& Frith, 1996), the involvement of mental imagery in hallucinations has proven to be a controversial issue. Using a signal-detection version of the White Christmas task, Bentall and Slade (1985a) investigated to what extent unusual vivid imagery may influence performance during an auditory detection task. They reasoned that if hallucinatory experiences were related to vivid mental imagery, participants reporting such experiences would perform poorly on signal-detection tasks due to a lowered sensitivity for external signals. Participants were assigned to a hallucination or control group on the basis of their scores on an instrument measuring the predisposition to hallucinate (Launay \& Slade, 1981). However, the authors found no difference in perceptual sensitivity between both groups. Yet, those who scored high on the hallucination measure displayed a heightened willingness to believe that an auditory signal was present. Several studies relying on various experimental paradigms support this finding, suggesting that vivid imagery per se does not account for reports of hallucinatory experiences (e.g. Aleman, Böcker, \& De Haan, 1999). Likewise, interrogative suggestibility (Young et al., 1987) and sensitivity to demand characteristics (Merckelbach \& Van de Ven, 2001) do not seem to predict performance on the White Christmas task.

Another individual difference measure that may be involved in normal individuals' reports of hallucinatory experiences is fantasy proneness. Fantasy proneness refers to a non-pathological trait defined by a deep and profound involvement in fantasy and imagination (Lynn \& Rhue, 1986). Individuals scoring high on fantasy proneness exhibit a general tendency to endorse odd or 
even bizarre items (e.g. Merckelbach, Horselenberg, \& Muris, 2001). For example, there are strong indications that paranormal experiences are commonly reported by fantasy prone individuals (e.g. Irwin, 1990). Likewise, fantasy proneness levels are significantly associated with endorsement of atypical symptoms listed by malingering instruments (e.g. Merckelbach \& Smith, in press). Interestingly, a number of studies noted that positive schizotypy overlaps with fantasy proneness (e.g. Merckelbach, Rassin, \& Muris, 2000). In a recent experiment, we found that fantasy proneness may also be involved in reports of hallucinatory experiences obtained during the White Christmas paradigm (Merckelbach \& Van de Ven, 2001). In that exploratory study, fantasy proneness, but not scores on the Launay-Slade Hallucination Scale (LSHS: Launay \& Slade, 1981) predicted undergraduates' reports of hallucinatory experiences. One possible explanation for this is that the White Christmas task capitalizes on a response bias to endorse and report bizarre symptoms rather than on the presence of genuine schizophrenia-like experiences.

In the current study, we made an attempt to replicate and extend our previous finding that fantasy proneness is related to hallucinatory reports in the White Christmas task (Merckelbach \& Van de Ven, 2001). Given the relatively small sample of our previous study $(N=47)$, the present study relied on a large sample of undergraduate students $(N=111)$. In addition, we administered two scales measuring schizophrenia-like phenomena as well as a self-report measure of mental imagery ability.

\section{Methods}

\subsection{Participants}

One hundred and eleven psychology or medical undergraduate students (23 men) volunteered to participate in the study in return for a small financial compensation. Their mean age was 20 years $(\mathrm{SD}=2.18$; range: $18-31$ years). Participants were told that the study was about auditory perception and to enhance the credibility of this cover story, they were asked to fill out a brief questionnaire about auditory impairments.

\subsection{Procedure and questionnaires}

We previously described our version of the White Christmas task (Merckelbach \& Van de Ven, 2001; see also Bentall \& Slade, 1985a). Briefly, participants were brought to a sound-isolated lab room. The full version of Bing Crosby's White Christmas song was presented to participants and following this, they were asked whether they were familiar with the song. All indicated they were. Next, they were told they would hear over headphones a tape with white noise for a 3-min period and that "the White Christmas song you just heard might be embedded in the white noise below the auditory threshold. If you think or believe you hear the song clearly, please press the button in front of you. Of course, you may press the button several times if you think that you heard several fragments of the song." Next, participants were to put on headphones, lights in the lab room were dimmed, and the tape with white noise was started. The tape did not contain any fragments of the White Christmas song. Frequency of button presses of each participant was recorded on-line. After the 3-min period, participants were asked to complete two $100 \mathrm{~mm}$ Visual 
Analogue Scales (VAS1 and VAS2). VAS1 asked whether and to what extent they heard the song (anchors: $0=\mathrm{I}$ have heard absolutely nothing of the song; $100=\mathrm{I}$ have heard the entire song very clearly), while VAS2 asked how confident they were about their VAS1 answer (anchors: $0=\mathrm{I}$ am absolutely not confident about my perception; $100=\mathrm{I}$ am absolutely confident about my perception). High scores on VAS1 indicate that participants believed they heard (fragments of) the song being played, while high scores on the VAS2 indicate that participants were very sure about this experience.

Next, participants were asked to complete the Schizotypal Personality Scale-A (STA: Claridge \& Broks, 1984; see also Rawlings, Claridge, \& Freeman, 2001), the LSHS (Launay \& Slade, 1981; see also Levitan, Ward, Catts, \& Hemsley, 1996), the shortened version of Bett's Questionnaire upon Mental Imagery (QMI: Sheehan, 1967), and the Creative Experiences Questionnaire (CEQ: Merckelbach et al., 2001).

The STA (Cronbach's alpha $=0.83$ ) is a 37 -item self-report questionnaire that intends to measure schizotypy. Items address unusual perceptual and cognitive experiences and are scored as true or false. Sample items are "Does your own voice ever seem distant, faraway?" and "Do things sometimes feel as if they are not real?" True-scores are summed to obtain a total score, such that a higher total score implies the presence of more schizotypal experiences.

The LSHS (Cronbach's alpha $=0.79$ ) is a widely used instrument for measuring the predisposition to hallucinate in both psychiatric and non-clinical samples. It consists of 12 statements that refer to hallucinatory experiences. Sample items are "I often hear a voice speaking my thoughts aloud" and "I have been troubled by hearing voices in my head". Participants score each item on a 5 -point scale $(0=$ certainly does not apply; $4=$ certainly applies; Bentall \& Slade, 1985b). Scores are summed to obtain a total score, with a higher total score indicating a stronger self-reported disposition towards hallucinatory experiences.

The QMI (Cronbach's alpha $=0.77$ ) is a 35-item self-report measure for individual differences in imagery ability. Items relate to several sensory modalities. Sample items are "How vividly and lively can you imagine the taste of salt?" and "How vividly can you imagine the miaowing of a cat?" Participants indicate on 7 -point scales $(1=$ as perfectly clear as if real; $7=\mathrm{I}$ think about it but I cannot imagine it) how vividly and lively they can imagine each item. Scores are summed to obtain a total score, such that a low total score implies high self-reported imagery ability.

The CEQ (Cronbach's alpha $=0.77$ ) is a 25 -item true-false index of fantasy proneness. Sample items are "As a child, I had my own make believe friend or animal" and "When I think of something cold, I actually get cold". True answers are summed to obtain a total score, with a higher total score implying a higher level of fantasy proneness.

\section{Results}

The records of three participants were excluded from data analyses, because they had not filled out all items of the questionnaires. Of the remaining 108 participants, $38(35 \%)$ pressed the button at least once, thus reporting that they had had hallucinatory-like experiences of hearing the White Christmas song. The mean frequency of button presses in this subsample was 3.92 $(\mathrm{SD}=3.0$; range 1-13). Table 1 shows the mean scores of those who pressed the button at least once and those who never pressed the button on VAS1, VAS2, STA, LSHS, QMI, and CEQ. 
Table 1

Mean scores (standard deviations) on VAS1, VAS2, STA, LSHS, QMI, and CEQ of participants with $(n=38)$ and without $(n=70)$ hallucinatory reports (control participants)

\begin{tabular}{lcc}
\hline Measures & Ss with hallucinatory reports & Control Ss \\
\hline VAS1* & $27.5(30.0)$ & $0.65(2.2)$ \\
VAS2* & $60.0(40.0)$ & $92.4(36.2)$ \\
STA & $11.5(5.5)$ & $10.1(5.9)$ \\
LSHS & $13.6(6.3)$ & $10.9(6.9)$ \\
QMI* & $89.2(26.6)$ & $105.5(33.0)$ \\
CEQ* & $7.5(3.9)$ & $5.6(3.4)$ \\
\hline
\end{tabular}

VAS1 = subjective perception rated on $100 \mathrm{~mm}$ Visual Analogue Scale; VAS2 = subjective confidence rated on $100 \mathrm{~mm}$ Visual Analogue Scale; STA = Schizotypal Personality Scale - A; QMI = shortened Bett's Questionnaire upon Mental Imagery; LSHS = Launay-Slade Hallucination Scale; CEQ = Creative Experiences Questionnaire.

* $P<0.05$, two-tailed.

Participants who reported hallucinatory experiences scored higher on VAS1 $[t(106)=-5.5$, $P<0.01]$, but lower on VAS2 $[t(106)=4.2, P<0.01]$ than those who never pressed the button. The two groups did not differ in terms of STA scores $[t(106)=-1.2, P=0.23]$. Those with hallucinatory reports scored marginally higher on LSHS than those without such reports, but this difference did not reach significance $[t(106)=-2.0, P=0.052]$. In terms of effect sizes (Cohen's $d$; Cohen, 1992), this difference was small $(d=0.39)$. Those with hallucinatory reports had significantly lower QMI scores (i.e. higher self-reported imagery ability) than those without such reports $[t(106)=2.6$, $P=0.01]$, a difference with a medium effect size $(d=0.51)$. In addition, those with hallucinatory reports had significantly higher CEQ scores than those without such reports $[t(106)=-2.5$, $P=0.02]$, which also represents a medium effect $(d=0.50)$.

Table 2 depicts Pearson product-moment correlations between individual difference measures. As can be seen, LSHS, STA, and CEQ were all positively correlated with each other (all $r$ 's $>0.6$, all $P$ 's $<0.01)$. Also, QMI and CEQ were significantly correlated with each other $(r=-0.48$, $P<0.01)$. To evaluate the unique contributions of self-reported imagery ability (QMI) and fantasy proneness (CEQ) to hallucinatory reports during the White Christmas task, we performed linear backward logistic regression with QMI, CEQ, and the interaction term as predictors and the presence (1) or absence (0) of button press as criterion. In the first step of the analysis, QMI was removed (Wald $=0.0, P=0.97$ ), while CEQ (Wald $=8.0, P<0.01$ ) and the interaction term (Wald $=3.9, P<0.05$ ) were retained in the second (final) step.

Table 2

Pearson product-moment correlations between individual difference measures

\begin{tabular}{lrrr}
\hline & STA & LSHS & QMI \\
\hline STA & & & \\
LSHS & $0.61^{*}$ & & \\
QMI & $-0.34^{*}$ & $-0.27^{*}$ & $-0.48^{*}$ \\
CEQ & $0.67^{*}$ & $0.60^{*}$ & \\
\hline
\end{tabular}

$* P<0.01$, two-tailed. 


\section{Discussion}

The current study relied on a modified version of the White Christmas task and a number of individual difference measures to examine in what way persons who report hallucinatory experiences differ from persons who do not. Our results can be catalogued as follows. To begin with, in line with many other studies (e.g. Barber \& Calverey, 1964; Bentall \& Slade, 1985a; Mintz \& Alpert, 1972; Young et al., 1987), we found that a non-trivial minority of participants reported having heard the White Christmas song, although this group was not very confident about their reports. Secondly, those with hallucinatory reports did not differ from those without such reports in terms of schizotypal traits, while both groups differed only marginally with respect to the predisposition to hallucinate. Thus, our results demonstrate that there is no straightforward connection between hallucinatory reports during the White Christmas task and schizophrenia-like symptoms reported by normal participants. Thirdly, those who reported hallucinatory experiences had higher self-reported mental imagery ability and scored higher on a measure of fantasy proneness than those without hallucinatory reports. We also found a considerable overlap between self-rated mental imagery ability and fantasy proneness. When this overlap was taken into account in a logistic regression analysis, fantasy proneness emerged as the best predictor for hallucinatory reports. This finding replicates our previous study (Merckelbach \& Van de Ven, 2001) that also found evidence for a link between fantasy proneness and hallucinatory reports.

Although there is now robust evidence that fantasy proneness is linked to reports of hallucinatory experiences obtained during the White Christmas test, the precise nature of this link remains unclear. One possibility is that such hallucinatory reports reflect fantasy prone individuals' pervasive tendency to endorse odd and bizarre items (Merckelbach et al., 2001). Note that individuals scoring high on fantasy proneness, as a rule, do not have genuine, life-like hallucinations. In fact, they adopt lax criteria when classifying internal experiences as hallucinations (Lynn \& Rhue, 1986). In line with this, fantasy prone individuals score relatively high on tests of malingering that ask for infrequent and unlikely symptoms (Merckelbach \& Smith, in press). Similarly, they seem to be more eager to endorse odd items when confronted with suggestive task instructions (Silva \& Kirsch, 1992), which fits nicely with Barber and Calverey's (1964) conclusion that the suggestive context of the White Christmas test will lead a subsample of normals to "testify that they [...] heard sounds that were not present" (p. 19). These considerations suggest that the White Christmas task is not a suitable task for eliciting genuine hallucinations in normal or clinical populations. Rather, this task capitalizes on a tendency to endorse all sorts of odd and unusual items, which does not necessarily correspond to the actual presence of odd and unusual experiences. This notion is also indirectly supported by the lack of a significant group difference on measures of schizophrenia-like symptoms, which contradicts the majority of findings reported in the literature on this topic (e.g. Claridge \& Broks, 1984; Morrison, Wells \& Nothard, 2000; Young et al., 1987). The more general implication would be that hallucinations reported by healthy fantasy prone individuals and those reported by psychotic patients do not form a continuum.

However, another and more complex account for the link between fantasy proneness and hallucinatory reports can be postulated. This account proceeds from the idea that fantasy proneness reflects a specific response bias that originates from impaired reality testing. Such an impaired reality testing might foster misattribution of internally generated experiences, which in turn may promote hallucinatory reports (e.g. Bentall, 1990; Cahill \& Frith, 1996). Indirect evidence for the 
idea of a specific response bias comes from studies finding a considerable overlap between fantasy proneness, schizophrenia-like phenomena, and dissociation (Merckelbach, Muris, Horselenberg, \& Stougie, 2000; Merckelbach, Rassin, \& Muris, 2000; Watson, 2001). The substantial correlations between fantasy proneness, schizotypy, and hallucinatory predispositions obtained in the current study provide some support for the idea that these measures define a common domain characterized by unusual cognitive and perceptual experiences that stem from impaired reality testing. This impaired reality testing has been interpreted as a manifestation of a disturbed sleepwake cycle (Watson, 2001) and/or "transliminality" (Thalbourne \& Houran, 2000), a concept that refers to aberrations in consciousness.

This line of argumentation is further strengthened by evidence showing that the frequency of hallucinatory reports in schizophrenic patients and normal controls increases when they are exposed to unstructured sensory stimuli (e.g. white noise) or when they are placed in a situation that involves partial sensory deprivation (e.g. Jakes \& Hemsley, 1987; Margo, Hemsley, \& Slade, 1981; McCreery \& Claridge, 1996). In contrast, the frequency of such reports decreases when participants are asked to direct their attention away from hallucinations, preferably in the direction of structured stimuli, like speech or music (Margo et al., 1981; see for treatment implications: Sukhwinder, Murray, \& McGuire, 1998). With this in mind, one could maintain that the white noise and partial sensory deprivation in our White Christmas paradigm elicited genuine hallucinatory experiences in high fantasy prone participants.

In sum, the current study documents that participants with hallucinatory reports score higher on fantasy proneness that those without such reports. Yet, we do not know whether this link only reflects a general response bias to endorse bizarre items or a subtle reality-testing deficit. Do these individuals only respond in a weird way or do they actually have weird experiences? Designing a critical study that could answer this question is extremely difficult because there is no easy way to circumvent self-reports when studying hallucinatory experiences.

\section{Acknowledgements}

We are indebted to Joke Conings for assisting in data acquisition, and to David Linden and the anonymous reviewers for useful comments on the manuscript.

\section{References}

Aleman, A., Böcker, K. B. E., \& De Haan, E. H. F. (1999). Disposition towards hallucinations and subjective versus objective vividness of imagery in normal subjects. Personality and Individual Differences, 27, 707-714.

Barber, T. X., \& Calverey, D. S. (1964). An experimental study of hypnotic (auditory and visual) hallucinations. Journal of Abnormal and Social Psychology, 68, 13-20.

Barrett, T. R., \& Etheridge, J. B. (1992). Verbal hallucinations in normals. I. People who hear 'voices'. Applied Cognitive Psychology, 6, 379-387.

Bentall, R. P. (1990). The illusion of reality: a review and integration of psychological research on hallucinations. Psychological Bulletin, 107, 82-95.

Bentall, R. P., Claridge, G. S., \& Slade, P. D. (1989). The multidimensional nature of schizotypal traits: a factor analytic study with normal subjects. British Journal of Clinical Psychology, 28, 363-375.

Bentall, R. P., \& Slade, P. D. (1985a). Reality testing and auditory hallucinations: a signal detection analysis. British Journal of Clinical Psychology, 24, 159-169. 
Bentall, R. P., \& Slade, P. D. (1985b). Reliability of a scale measuring disposition towards hallucinations: a brief report. Personality and Individual Differences, 6, 527-529.

Cahill, C., \& Frith, C. D. (1996). A cognitive basis for the signs and symptoms of schizophrenia. In C. Pantelis, H. E. Nelson, \& T. R. E. Barnes (Eds.), Schizophrenia: a neuropsychological perspective (pp. 373-397). New York: Wiley.

Claridge, G., \& Broks, P. (1984). Schizotypy and hemisphere function: I. Theoretical consideration and the measurement of schizotypy. Personality and Individual Differences, 5, 633-648.

Cohen, J. (1992). A power primer. Psychological Bulletin, 112, 155-159.

Irwin, H. J. (1990). Fantasy proneness and paranormal beliefs. Psychological Reports, 66, 655-658.

Jakes, S., \& Hemsley, D. R. (1987). Personality and reports of hallucination and imagery in a normal population. Perceptual and Motor Skills, 64, 765-766.

Launay, G., \& Slade, P. D. (1981). The measurement of hallucinatory predisposition in male and female prisoners. Personality and Individual Differences, 2, 221-234.

Loughland, C. M., \& Williams, J. M. (1997). A cluster analytic study of schizotypal trait dimensions. Personality and Individual Differences, 23, 877-883.

Levitan, C., Ward, P. B., Catts, S. V., \& Hemsley, D. R. (1996). Predisposition toward auditory hallucinations: the utility of the Launay-Slade Hallucination Scale in psychiatric patients. Personality and Individual Differences, 21, 287-289.

Lynn, S. J., \& Rhue, J. W. (1986). Fantasy proneness: hypnosis, developmental antecedents, and psychopathology. Journal of Personality and Social Psychology, 51, 404-408.

Margo, A., Hemsley, D. R., \& Slade, P. D. (1981). The effects of varying auditory input on schizophrenic hallucinations. British Journal of Psychiatry, 139, 122-127.

McCreery, C., \& Claridge, G. (1996). A study of hallucinations in normals-I. Self-report data. Personality and Individual Differences, 21, 739-747.

Merckelbach, H., Horselenberg, R., \& Muris, P. (2001). The creative experiences questionnaire (CEQ): a brief selfreport measure of fantasy proneness. Personality and Individual Differences, 31, 987-995.

Merckelbach, H., Muris, P., Horselenberg, R., \& Stougie, S. (2000). Dissociative experiences, response bias, and fantasy proneness in college students. Personality and Individual Differences, 28, 49-58.

Merckelbach, H., Rassin, E., \& Muris, P. (2000). Dissociation, schizotypy, and fantasy proneness in undergraduate students. Journal of Nervous and Mental Disease, 188, 428-431.

Merckelbach, H., \& Smith, G. P. Diagnostic accuracy of the Structured Inventory of Malingered Symptomatology (SIMS) in detecting instructed malingering. Archives of Clinical Neuropsychology (in press).

Merckelbach, H., \& Van de Ven, V. (2001). Another White Christmas: fantasy proneness and reports of 'hallucinatory experiences' in undergraduate students. Journal of Behavior Therapy and Experimental Psychiatry, 32, 137-144.

Mintz, S., \& Alpert, M. (1972). Imagery vividness, reality testing and schizophrenic hallucinations. Journal of Abnormal Psychology, 79, 310-316.

Morrison, A. P., Wells, A., \& Nothard, S. (2000). Cognitive factors in predisposition to auditory and visual hallucinations. British Journal of Clinical Psychology, 39, 67-78.

Rawlings, D., Claridge, G., \& Freeman, J. L. (2001). Principal components analysis of the Schizotypal Personality Scale (STA) and the Borderline Personality Scale (STB). Personality and Individual Differences, 31, 409-419.

Sheehan, P. W. (1967). A shortened form of Bett's questionnaire upon mental imagery. Journal of Clinical Psychology, 23, 386-389.

Silva, C. E., \& Kirsch, I. (1992). Interpretive sets, expectancy fantasy proneness, and dissociation as predictors of hypnotic response. Journal of Personality and Social Psychology, 63, 847-856.

Sukhwinder, S. S., Murray, R. M., \& McGuire, P. K. (1998). Auditory hallucinations: a review of psychological treatments. Schizophrenia Research, 32, 137-150.

Thalbourne, M. A., \& Houran, J. (2000). Transliminality, the Mental Experiences Inventory and tolerance to ambiguity. Personality and Individual Differences, 28, 853-863.

Watson, D. (2001). Dissociations of the night: Individual differences in sleep-related experiences and their relation to dissociation and schizotypy. Journal of Abnormal Psychology, 110, 526-535.

Young, H. F., Bentall, R. P., Slade, P. D., \& Dewey, M. E. (1987). The role of brief instructions and suggestibility in the elicitation of auditory and visual hallucinations in normal and psychiatric subjects. Journal of Nervous and Mental Disease, 175, 41-48. 